\title{
Neutrophil function in children with acute lymphoblastic leukaemia in the presence and absence of viral infections
}

\author{
M. M. REID, A. W. CRAFT, AND W. T. LOW \\ Royal Victoria Infirmary, Newcastle upon Tyne
}

SUMMARY Neutrophil function was assessed regularly in 26 children with acute lymphoblastic leukaemia (ALL) in remission, both when they were well and during viral infections. Tests of candidacidal ability when these children were apparently free of infection showed a trend towards lower levels compared with controls. The most pronounced depression of candidacidal ability and chemotaxis was during viral infections, and these two functions of neutrophils were more likely to be abnormal then than when the children were free of infection. In children with ALL in remission, whose neutrophils may function abnormally even when they are well, the risk of acquiring bacterial or fungal infections may be made greater by virus infections.

Infection is a major cause of death for children with ALL, particularly during remission (Hughes 1971; Craft et al., 1977). Although viruses are increasingly being incriminated in the deaths of such children, overwhelming bacterial or fungal infections still account for many deaths. Profound neutropenia is not always associated with such deaths. Several of the deaths recently reported from Newcastle were associated with coexistent viral and bacterial infections (Craft et al., 1977). The interaction of such infections is poorly understood. As part of a larger survey of infection and immunity in children with ALL in remission, neutrophil function was assessed to discover whether any defects were detectable and, if so, whether they could be related to the presence of infection.

\section{Patients}

Between June 1975 and October 1976, 27 children with ALL presenting consecutively to one of two major hospitals in Newcastle upon Tyne were entered into the study. Their ages at diagnosis ranged from one to 10 years. One patient died before remission

\footnotetext{
Paediatric Department, Newcastle General Hospital, Newcastle upon Tyne

M. M. REID, registrar

Department of Child Health, Royal Victoria Infirmary, Newcastle upon Tyne

A. W. CRAFT, consultant paediatrician

Victoria Hospital, Kirkcaldy, Fife

w. T. Low, senior chief technician
}

was induced. The remaining 26 patients were followed up, while in remission, for periods ranging from 4 months to 2 years. All were receiving a modified version of an ALGB 6801 regimen (Reid et al., 1977). The children were assessed if possible at regular monthly intervals and when infection was suspected. At times, insufficient blood was obtained and some tests could not be performed. Routine testing was not carried out at diagnosis because it was usually impossible to obtain adequate numbers of neutrophils.

\section{Controls}

Neutrophil function tests were controlled with cells from laboratory staff. Reference ranges were derived from results obtained from 20 staff members and from 6 children, aged 3 to 11 years, admitted to hospital with noninfective conditions.

\section{Methods}

Neutrophils were separated by centrifuging white blood cell-rich plasma from dextran-sedimented blood over a Ficoll-Triosil (Lymphoprep, Nygaard) gradient.

Stimulated nitrobluetetrazolium (NBT) reduction was assessed on whole blood samples by the method of Segal and Peters (1975). Results were expressed as arbitrary spectrophotometer units $/ 10^{6}$ neutrophils.

Chemotaxis was assessed by a method based on that of Wilkinson (1974). Results were expressed as 
the distance in $\mu \mathrm{m}$ travelled by the leading front of neutrophils into the micropore filter.

Killing ability was assessed using Candida albicans as the test organism by a method based on that of Goldman and Th'ng (1973). Results were expressed as the percentage of $C$. albicans killed.

Virus infections were diagnosed by immunofluorescent techniques and culture (Gardner and McQuillin, 1974).

During the period of the survey there was no occasion on which adequate numbers of neutrophils were obtained from children with bacterial or fungal infections.

\section{Results}

The results of tests of NBT reduction, killing ability, and chemotaxis in the children with ALL, both in the presence and absence of virus infections, are shown in Figs 1, 2, and 3. The reference adult and child

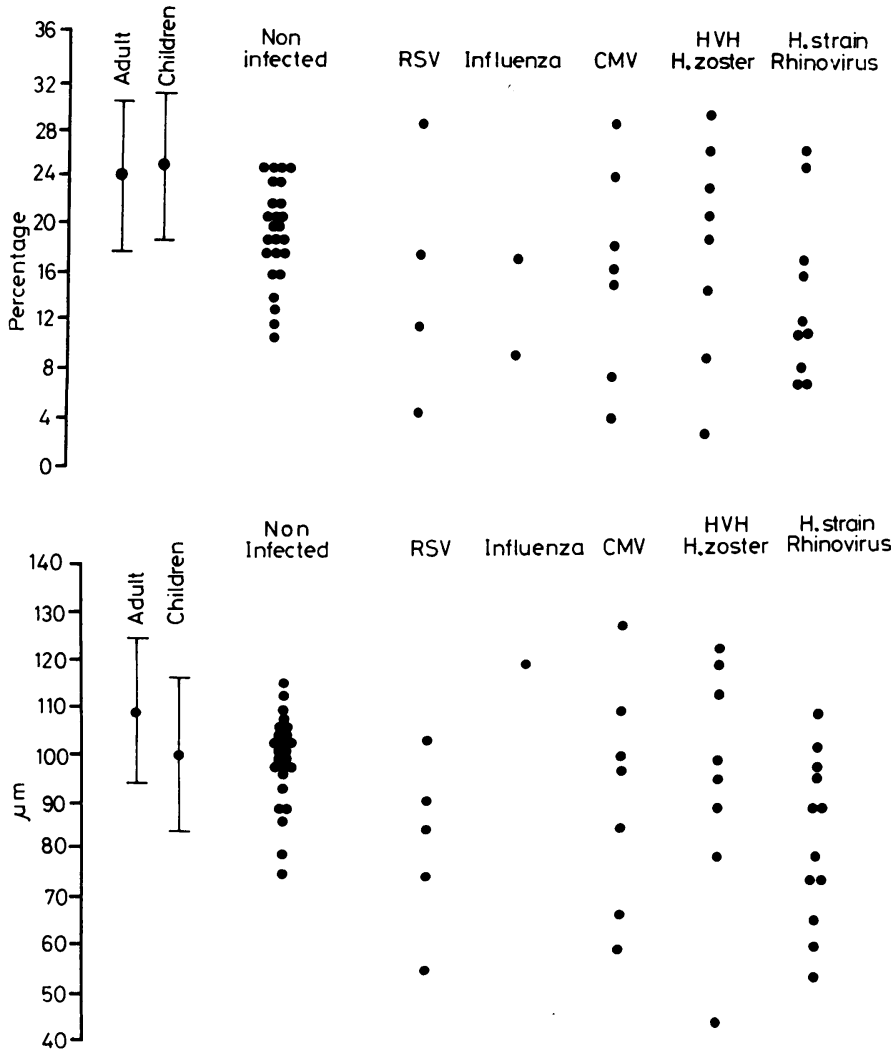

Fig. 1 Stimulated NBT reduction in children with $A L L$ when well and during virus infections with reference ranges (mean $\pm S D$ ) for children and adults.

RSV = respiratory syncytial virus

CMV = cytomegalovirus

HVH $=$ herpesvirus hominis

H. zoster $=$ Herpes zoster

Fig. 2 Neutrophil candidacidal ability in children with $A L L$ when well and during virus infections, with reference ranges (mean $\pm S D)$ for children and adults.

Fig. 3 Neutrophil chemotaxis in children with $A L L$ when well and during virus infections, with reference ranges (mean $\pm S D)$ for children and adults. 
Table 1 Killing ability. Summary of 'normal' and 'abnormal' results in noninfected and infected children with $A L L$

\begin{tabular}{lll}
\hline & Noninfected & Infected \\
\hline Normal tests & 96 & 14 \\
Abnormal tests & 47 & 17 \\
$\quad$ Totals & 143 & 31 \\
\hline
\end{tabular}

Table 2 Chemotaxis. Summary of 'normal' and 'abnormal' results in noninfected and infected children with $A L L$

\begin{tabular}{lll}
\hline & Noninfected & Infected \\
\hline Normal tests & 134 & 21 \\
Abnormal tests & 22 & 12 \\
Totals & 156 & 33 \\
\hline
\end{tabular}

ranges are given for comparison. Each point in the noninfected group represents a mean of all tests performed in an individual child when no infection could be detected. One of the 26 children was at no time tested when free of infection. All other points represent the results of a single test. The mean value of killing ability ( \pm SD) in the children with ALL when they were free of infection is $19 \%( \pm 4)$. The reference adult range is $25 \%( \pm 6)$. This difference is significant (Student's $t, \mathrm{P}<0 \cdot 01$ ).

Tables 1 and 2 give a summary of the results of all the individual tests of killing ability and chemotaxis. Results which are described as 'abnormal' are all below the lowest point on the reference ranges for the appropriate test. Killing ability was more likely to be 'abnormally' low $(<18 \%)$ in infected than noninfected children $\left(\chi^{2}=5 \cdot 3, P<0 \cdot 05\right)$. Chemotaxis was also more likely to be 'abnormal' $(<84 \mu \mathrm{m})$ in infected children $\left(\chi^{2}=4 \cdot 6, P<0 \cdot 05\right)$.

There was no obvious change in the pattern of results with time, nor did the stage of treatment appear to affect them.

\section{Discussion}

There was no difference in NBT reduction and chemotaxis between the control populations and the children with ALL when not infected. However the results of tests of killing ability in such children (Fig. 2) suggest there was some impairment, as there was a trend towards lower levels than was found in the normal population. Quantitative assessment of killing ability is simplified if C. albicans is used as the test organism. It is probably killed by the hydrogen peroxide mechanism, as are many bacteria.

However, tests of candidacidal ability may not be comparable with those of bactericidal ability. Few defects in neutrophil function during remission of
ALL have been reported. Strauss et al. (1970) reported a bactericidal defect in 4 of 6 patients in remission. Gregory et al. (1972) described a bactericidal defect in a group of children most of whom were in remission. Baehner et al. (1973) found a temporary bactericidal defect associated with craniospinal irradiation, but not at any other time in remission. Sarab-el-Nakeeb and Thompson (1977) reported abnormal chemotaxis in children with ALL in remission. Bactericidal defects have also been described during relapse of ALL (Strauss et al., 1970; Humbert et al., 1976).

Depression of neutrophil function by viruses in normal subjects has been demonstrated in vitro (Larson and Blades, 1976; Larson et al., 1977; Ruutu et al., 1977). Normal children with virus infections also have abnormally functioning neutrophils (Anderson et al., 1976; Craft et al., 1976). The present study did not show significant depression of NBT reduction in children with ALL by virus infections. However a striking depression of killing ability and chemotaxis in some of these children took place during virus infections.

Virus infections may therefore be associated with depression of neutrophil function in a group of children whose neutrophils may already be adversely affected by their leukaemia or by treatment. This depression of function, in addition to the risks of neutropenia, may make children with ALL even more susceptible to bacterial and fungal infections, and shows the seriousness of comparatively common viruses to such children.

M.M.R. was supported by a grant from the Tyneside Leukaemia Research Association. We are grateful to the other members of the Newcastle Leukaemia Research Group: Drs J. Kernahan, T. C. Noble, C. R. Pullen, P. R. A. Taylor, Professor P. S. Gardner, Professor W. Walker, and Miss J. McQuillin.

\section{References}

Anderson, R., Rabson, A. R., Sher, R., and Koornhof, H. J. (1976). Defective neutrophil motility in children with measles. Journal of Pediatrics, 89, 27-32.

Baehner, R. L., Neiburger, R. G., Johnson, D. E., and Murrmann, S. M. (1973). Transient bactericidal defect of peripheral blood phagocytes from children with acute lymphoblasticleukaemia receiving cranio-spinal irradiation. New England Journal of Medicine, 289, 1209-1213.

Craft, A. W., Reid, M. M., and Low, W. T. (1976). The effect of virus infections on polymorph function in children. British Medical Journal, 1, 1570.

Craft, A. W., Reid, M. M., Bruce, E., Kernahan, J., and Gardner, P. S. (1977). Role of infection in the death of children with acute lymphoblastic leukaemia. Archives of Disease in Childhood, 52, 752-757. 
Gardner, P. S., and McQuillin, J. (1974). Rapid Virus Diagnosis: Application of Immunofluorescence. Butterworth: London.

Goldman, J. M., and Th'ng, K. H. (1973). Phagocytic function of leucocytes from patients with acute myeloid and chronic granulocytic leukaemia. British Journal of Haematology, 25, 299-308.

Gregory, L., Williams, R., and Thompson, E. (1972). Leucocyte function in Down's syndrome and acute leukaemia. Lancet, 1, 1359-1361.

Hughes, W. T. (1971). Fatal infections in childhood leukemia. American Journal of Diseases of Children, 122, 283-287.

Humbert, J. R., Hutter, J. J., Jr, Thoren, C. H., and De Armey, P. A. (1976). Decreased neutrophil bactericidal activity in acute leukemia of childhood. Cancer, 37, 21942200.

Larson, H. E., and Blades, R. (1976). Impairment of human polymorphonuclear leucocyte function by influenza virus. Lancet, 1, 283.

Larson, H. E., Parry, R. P., Gilchrist, C., Luquetti, A., and Tyrrell, D. A. J. (1977). Influenza virus and staphylococci in vitro: some interactions with polymorphonuclear leucocytes and epithelial cells. British Journal of Experimental Pathology, 58, 281-288.
Reid, M. M., Craft, A. W., and Todd, J. A. (1977). Serial numbers of circulating $\mathbf{T}$ and $\mathbf{B}$ lymphocytes in children with acute lymphoblastic leukaemia. Archives of Disease in Childhood, 52, 245-247.

Ruutu, P., Vaheri. A., and Kosunen, T. U. (1977). Depression of human neutrophil motility by influenza virus in vitro. Scandinavian Journal of Immunology, 6, 897-906.

Sarab-el-Nakeeb, and Thompson, E. N. (1977). Chemotaxis and random migration of neutrophils in acute lymphoblastic leukaemia in childhood (abstract). Archives of Disease in Childhood, 52, 822-823.

Segal, A. W., and Peters, T. J. (1975). The nylon column dye test: a possible screening test for phagocytic function. Clinical Science and Molecular Medicine, 49, 591-596.

Strauss, R. R., Paul, B. B., Jacobs, A. A., Simmons, C., and Sbarra, A. J. (1970). The metabolic and phagocytic activities of leukocytes from children with acute leukemia. Cancer Research, 30, 480-488.

Wilkinson, P. C. (1974). Chemotaxis and Inflammation. Churchill Livingstone: Edinburgh.

Correspondence to Dr M. M. Reid, Department of Haematology, Royal Victoria Infirmary, Newcastle upon Tyne NE1 4LP.

The following articles will appear in future issues of this journal:

Vertical transmission of hepatitis B surface antigen in carrier mothers in two west London hospitals. D. Woo, M. Cummins, P. A. Davies, D. R. Harvey, R. Hurley, and A. P. Waterson.

Non-neuropathic Gaucher disease presenting in infancy. P. Hodgson, J. Goldblatt, and P. Beighton.

Childhood cystinuria in New South Wales. Results in children who were followed up after being detected by urinary screening in infancy. A. Smith, J. S. Yu, and D. A. Brown.

Nutritional status of light-for-date infants at birth and its influence on early postnatal growth. D.P. Davies, P. Platts, J. M. Pritchard, and P. W. Wilkinson.

Numerical evaluation of facial pattern in children with isolated pulmonary stenosis. H. Ainsworth, J. Hunt, and M. Joseph.

Infantile hypertrophic pyloric stenosis-unusual familial incidence. $V . R$. Finsen. 